\title{
Pengembangan Media Puppet Book Berbasis Pembelajaran Multiliterasi pada Peserta Didik Sekolah Dasar
}

\author{
Ayi Solihat*, Nana Hendracipta, Rina Yuliana \\ Universitas Sultan Ageng Tirtaysa Serang, Indonesia \\ Ayisolihat31@gmail.com*
}

\begin{abstract}
Books as a medium of literacy are presented normally, making students less interested. Developing puppet media needs to be done. This research aims to develop Puppet Book media. This research method, R\&D with Borg and Gall research design. The results of the study were in the form of a one-horned rhinoceros puppet learning media complete with books and audio attached to the puppets. The results of the validation of media experts (average value 90.285\%), linguists (average value 99.167\%), material experts (average value 92.105\%). The results of validation (media, language, material) with a very decent category. The results of the questionnaire responses of students in field trials showed $96.41 \%$ with very good criteria. Based on these results, the final product in the form of a puppet book based on multiliteration learning is suitable for the learning activities of fourth grade elementary school students.
\end{abstract}

Key Words: learning media; multiliteration; puppet book

\begin{abstract}
Abstrak: Buku sebagai media literasi yang disajikan biasa, membuat peserta didik kurang tertarik. Pengembangkan media puppet perlu dilakukan. Penelitian ini bertujuan untuk mengembangkan media Puppet Book. Metode penelitian ini, R\&D dengan desain penelitian Borg and Gall. Hasil penelitian berupa media pembelajaran puppet badak bercula satu yang dilengkapi buku serta audio yang terpasang pada puppet. Hasil validasi ahli media (nilai rata- rata 90,285\%), ahli bahasa (nilai rata- rata 99,167\%), ahli materi (nilai rata- rata 92,105\%). Hasil validasi (media, bahasa, materi) dengan kategori sangat layak. Hasil angket respon siswa pada uji coba lapangan menunjukan 96,41\% dengan kriteria sangat baik. Berdasarkan hasil tersebut, produk akhir berupa puppet book berbasis pembelajaran multiliterasi layak digunakan untuk kegiatan belajar siswa kelas IV SD.
\end{abstract}

Kata kunci: media pembelajaran; multiliterasi; puppet book

\section{Pendahuluan}

Memasuki abad ke-21 pembelajaran literasi menjadi salah satu kegiatan pembiasaan di Sekolah Dasar. Hal ini bertemali dengan tuntutan kompetensi- kompetensi peserta didik yang harus dikuasai di abad 21 yang menurut Morocco,et al, yaitu pemahaman yang tinggi, kritis dalam berpikir, kreatif dalam berkomunikasi dan berkolaborasi serta kreatif dalam berpikir (Abidin, 2017). Pembelajaran literasi kemudian berkembang menjadi pembelajaran multiliterasi. Pembelajaran multiliterasi terhubung dengan keterampilan membaca, menulis, berbahasa lisan dan ber-IT yang terhubung dengan kompetensi belajar di abad 21 yakni (1) kreativitas dan inovasi, (2) berpikir kritis, pemecahan masalah dan pembuatan keputusan (3) metakognisi, (4) komunikasi, (5) kolaborasi, (6) literasi informasi, (7) literasi teknologi informasi, (8) sikap berkewarganegaraan, (9) berkehidupan dan berkarier, (10) 
responsibilitas personal dan sosial, termasuk kesadaran atas kompetensi dan budaya (Abidin, 2017).

Berdasarkan survei yang telah dilakukan TIMSS dan PIRLS (Ratnawati, 2018) menunjukkan perolehan skor membaca pemahaman siswa kelas IV SD di Indonesia hanya mencapai skor 428, jauh dari rata-rata skor internasional yaitu 500. Sama halnya dengan hasil membaca dalam Programme for International Student Assessment (PISA), menunjukan peserrta Indonesia menduduki posisi bawah, terlihat dari keterangan peringkat dengan jumlah negara partisipan.

Tabel 1. Capaian Indeks PISA Indonesia Tahun 2000- 2015

\begin{tabular}{|c|c|c|c|c|c|}
\hline Tahun & Materi yang Diujikan & $\begin{array}{l}\text { Skor Rata- rata } \\
\text { Indonesia }\end{array}$ & $\begin{array}{l}\text { Skor Rata- rata } \\
\text { Internasional }\end{array}$ & $\begin{array}{l}\text { Peringkat } \\
\text { Indonesia }\end{array}$ & $\begin{array}{c}\text { Jumlah } \\
\text { Negara } \\
\text { Partisipan }\end{array}$ \\
\hline & Membaca & 371 & 500 & 39 & \\
\hline \multirow[t]{3}{*}{2000} & Matematika & 367 & 500 & 39 & 41 \\
\hline & Sains & 393 & 500 & 38 & \\
\hline & Membaca & 382 & 500 & 39 & \\
\hline \multirow[t]{3}{*}{2003} & Matematika & 360 & 500 & 38 & 40 \\
\hline & Sains & 395 & 500 & 38 & \\
\hline & Membaca & 393 & 500 & 48 & \\
\hline \multirow[t]{3}{*}{2006} & Matematika & 396 & 500 & 50 & 56 \\
\hline & Sains & 393 & 500 & 50 & \\
\hline & Membaca & 402 & 500 & 57 & \\
\hline \multirow[t]{3}{*}{2009} & Matematika & 371 & 500 & 61 & 65 \\
\hline & Sains & 383 & 500 & 60 & \\
\hline & Membaca & 396 & 500 & 62 & \\
\hline \multirow[t]{3}{*}{2012} & Matematika & 375 & 500 & 64 & 65 \\
\hline & Sains & 382 & 500 & 64 & \\
\hline & Membaca & 397 & 500 & 61 & \\
\hline \multirow[t]{2}{*}{2015} & Matematika & 386 & 500 & 63 & 69 \\
\hline & Sains & 403 & 500 & 62 & \\
\hline
\end{tabular}

Diolah dari hasil laporan PISA OECD, 2018. (Pratiwi, 2017)

Hasil Asesmen Kompetensi Siswa Indonesia (AKSI)/Indonesia National Assessment Programme (INAP) yang menguji kemampuan membaca, matematika, dan sains pada siswa sekolah dasar menunjukkan hasil yang serupa. Secara nasional, untuk kategori kurang dalam membaca adalah 46,83 persen (Tim GLN Kemendikbud, 2017). Rendahnya minat baca tersebut mendorong Kemendikbud mengembangkan Gerakan Literasi Sekolah (GLS) sesuai 
Peraturan Menteri Pendidikan dan kebudayaan Nomor 23 Tahun 2005 yang salah satu gerakannya yaitu membaca buku nonpelajaran sebelum belajar dimulai selama 15 menit

Studi pendahuluan telah dilakukan peneliti di SDN Terondol Kota Serang. Tujuannya untuk mengetahui permasalahan kegiatan literasi dalam pembelajaran. Berdasarkan hasil observasi peneliti sejak tanggal 25 September 2019 - 19 Oktober 2019, yang dilakukan di kelas IV-A diketahui bahwa, sebelum pembelajaran dimulai guru kelas jarang menerapkan kegiatan literasi. Pada saat pembelajaran beliau jarang menggunakan media pembelajaran dan cenderung menyajikan pembelajaran secara konvensional yakni ceramah, tanya jawab dan penugasan. Ketika pembelajaran berlangsung, beliau hanya memanfaatkan buku paket guru atau buku paket siswa serta LKS. Oleh sebab itu peserta didik terlihat kurang antusias dalam belajar dan terlihat bosan mengikuti pembelajaran.

Salah satu media untuk pembiasaan literasi adalah buku. Buku merupakan media pembelajaran konvensional namun peran buku sangat dibutuhkan guna memudahkan guru mennyampaikan materi dan memudahkan siswa memahami materi. Buku yang disajikan biasa, membuat peserta didik kurang tertarik terhadap buku. Berdasarkan hal tersebut peneliti memilih mengembangkan media berjenis buku dengan penambahan puppet, karena menurut (Sudjana \& Rivai, 2010) boneka ialah jenis model yang bisa dipergunakan untuk memperlihatkan permainan. Puppet juga dipandang sebagai media yang sesuai dengan karakter siswa SD, sesuai dengan pendapat (Desmita, 2009) mengatakan bahwa siswa sd masih menyukai kegiatan bermain, bergerak dan menyukai kegiatan secara berkelompok. Puppet book ini merupakan inovasi peneliti dalam memvariasikan tampilan buku. Media puppet book terdiri atas tiga komponen, komponen pertama terdapat buku yang berisikan cerita fiksi dan nonfiksi yang digunakan untuk melatih pemahaman peserta didik melalui membaca, komponen kedua audio yang bisa digunakan peserta didik untuk kemampuan menyimak melalui mendengarkan dan komponen ketiga ialah puppet yang bisa dimainkan oleh peserta didik atau guru dalam bercerita.

Puppet book merupakan media pembelajaran audio visual yakni media pembelajaran yang bersuara dan bergambar (Rusman, 2012). Puppet book yang dikembangkan merupakan jenis hand puppet yakni boneka tangan. Puppet atau boneka tangan adalah boneka yang dimainkan oleh tangan dan dijadikan salah satu media dalam kegiatan pembelajaran (Joko Sulianto et al., 2014). Puppet book ini dibuat dengan prinsip media pembelajaran multiliterasi. Menurut Ogle multiliterasi diartikan sebagai pembelajaran yang menempatkan kemampuan berbahasa guna meningkatkan kemampuan berpikir yakni mengkritisi, menganalisis, mengevaluasi informasi dari segala sumber dan kemampuan mengtransferkan informasi yang didapat (Abidin, 2017).

Penelitian terkait puppet book pernah diteliti oleh Senen, Ameliandari, Pujiastuti, and Purwanti (2020) bahwa media puppet book dapat meningkatkan keterampilan berpikir tingkat tinggi dan karakter siswa. Menurut (Fakhrudin \& Inayati, 2015) media puppet book atau media boneka tangan membuat siswa memahami materi ajar sehingga dapat meningkatkan hasil belajar siswa (Fakhrudin \& Inayati, 2015). Penelitian ini berbeda dengan penelitian sebelumnya, novelty dari penelitian adalah media puppet book terdiri dari cerita fiksi dan nonfiksi, terdapat audio dan media dapat dimainkan oleh siswa atau guru dalam 
bercerita. Tujuan penelitian ini adalah mengembangkan media puppet book yang berbasis pembelajaran multiliterasi yang valid.

\section{Metode}

Penelitian ini dilakukan di SDN Terondol Kota Serang dengan sasaran penelitiannya ialah siswa kelas IV. Menggunnakan metode penelitian dan pembembangan (Research and Development). Penelitian hendak dilakukan sesuai dengan desain pengembangan yang dilakukan oleh Borg and Gall yang dimodifikasi meliputi (1) need assessment, dilakukan dengan menganalisis kebutuhan dari permasalahan yang ada yang kemudian dianalisis berdasarkan studi literatur dan studi lapangan. (2) pengumpulan data, yakni mengumpulkan berbagasi informasi dan studi literatur yang berkaitan dengan media yang sedang dikembangkan. (3) Desain produk, yakni merancang desain media yang terdiri atas puppet badak cula satu, buku bacusa, dan audio. (4) validasi atau uji ahli, tujuannya adalah untuk mengetahui ketercapaian kriteria media yang dikembangkan. Uji validasi ini dilakukan kepada tiga ahli yakni media, bahasa, dan materi. (5) Revisi produk, dilakukan sesuai dengan kritik dan saran tim ahli validasi yang tujuannya untuk memperbaiki kekurangan dan desain produk yang dibuat. (6) Uji coba produk. Dalam hal ini pengujicobaan secara terbatas dilakukan pada siswa kelas IV di SDN Terondol kota Serang guna mengetahui respon siswa terhadap ketertarikannya pada media puppet book. (Sugiyono, 2016).

Data dikumpulkan dengan menggunakan teknik (1) observasi, (2) angket (3) wawancara, dan (4) dokumentasi. Sedangkan untuk mengukur kelayakan produk menggunakan teknik analisis pengolahan data dengan menggunakan rumus :

$$
\text { NP }: \frac{R}{S M} \times 100 \%
$$

(Ngalim Purwanto, 2009)

Keterangan :

NP : Nilai Presentase kelayakan yang diharapkan

R : : Skor mentah yang diperoleh

SM : Skor maksimal ideal

Kriteria interpretasi skor persentase yang didapatkan dari uji kelayakan penilaian ahli pada tabel berikut :

\begin{tabular}{cc}
\multicolumn{2}{c}{ Tabel $\mathbf{2}$ Kriteria Interpretasi Skor } \\
\hline Nilai Kualitatif & Skor \\
\hline Sangat Layak & 5 \\
\hline Layak & 4 \\
\hline Cukup Layak & 3 \\
\hline Kurang Layak & 2 \\
\hline Tidak Layak & 1 \\
\hline \multicolumn{2}{c}{ (Sugiyono, 2016) }
\end{tabular}

Nilai yang diperoleh kemudian di interpretasikan sesuai dengan kriteria dibawah ini : 
Tabel 3 Kriteria Kategori Interpretasi

\begin{tabular}{cc}
\hline Presentase pencapaian & Interpretasi \\
\hline $0-20 \%$ & Tidak Layak \\
\hline $21-40 \%$ & Kurang Layak \\
\hline $41-60 \%$ & Cukup Layak \\
\hline $61-80 \%$ & Layak \\
\hline $81-100 \%$ & Sangat Layak \\
\hline
\end{tabular}

(Dimodifikasi dari (Riduwan, 2010)

Data angket dikelola menggunakan skala Likert. Setiap siswa diminta untuk menjawab pernyataan yang tersedia dengan pilihan Setuju (S) dan Tidak Setuju (TS). Penyataan positif dengan nilai Setuju $(S)=2$ dan Tidak Setuju $(T S)=1$, sedangkan jika pernyataan negatif Setuju $(S)=1$ dan Tidak Setuju $(T S)=2$. Mendeskripsikan hasil angket siswa terhadap ketertarikan siswa pada media puppet book berbasis pembelajaran multiliterasi yang dibuat oleh peneliti, maka dihitung dengan rumus berikut:

$$
\mathrm{NP}=\frac{n}{N} \times 100 \%
$$

(Arikunto, 2019)

\section{Keterangan:}

NP : Persentase sikap siswa setiap indikator.

n : Jumlah skor siswa untuk setiap indikator.

$\mathrm{N} \quad$ : Jumlah skor total untuk setiap indikator

Selanjutnya mencari nilai rata- rata dari seluruh indikator, dengan menggunakan rumus:

$$
\overline{\mathrm{x}}=\frac{\sum x_{i}}{n}
$$

(Sudjana, 2016)

\section{Keterangan :}

$$
\begin{array}{ll}
\overline{\mathbf{x}} & \text { : Nilai rata- rata } \\
\sum \boldsymbol{x}_{\boldsymbol{i}} & \text { : jumlah seluruh nilai data } \\
\mathrm{n} & \text { : jumlah indikator }
\end{array}
$$

Hasil penilaian yang diperoleh diinterpretasikan berdasarkan tabel dibawah ini :

\begin{tabular}{cc}
\multicolumn{2}{c}{ Tabel 4 Kriteria Interpretasi Respon Siswa } \\
\hline Presentase Pencapaian & Interpetasi \\
\hline $81 \%-100 \%$ & Sangat Baik \\
\hline $61 \%-80 \%$ & Baik \\
\hline $41 \%-60 \%$ & Cukup Baik \\
\hline $21 \%-40 \%$ & Kurang Baik \\
\hline $0 \%-20 \%$ & Tidak Baik \\
\hline & Sumber: (Riduwan, 2010)
\end{tabular}




\section{Hasil dan Pembahasan}

Penelitian pengembangan telah dilakukan berdasarkan tahapan pengembangan Borg and Gall yang dimodifikasi oleh Sugiyono. Tahapan pengembangan yang telah dilalui diantaranya: (1) need assessment, penetapan pembahasan pada tema 4 Berbagai Pekerjaan, KD 3.5 Menguraikan pendapat pribadi tentang isi buku sastra (cerita, dongeng dan sebagainya) dan 4.5 Mengomunikasikan pendapat pribadi tentang isi buku sastra yang dipilih dan dibaca sendiri secara lisan dan tulis yang didukung oleh alasan. Indikator 3.5.1 Menyebutkan sifat- sifat tokoh dan membandingkannya dengan rinci. 4.5.2 Menyampaikan pendapatnya mengenai sifat tokoh yang patut dicontoh, baik secara lisan maupun tulisan dengan sistematis. (2) pengumpulan data, mengumpulkan informasi dari studi literatur mengenai puppet book dan pembelajaran multiliterasi. (3) Desain produk, Puppet bacusa berukuran $45 \mathrm{~cm} \times 30 \mathrm{~cm}$.

Puppet bacusa terbuat dari kain velboa berwarna abu- abu. Sisi kiri puppet bacusa terdapat kantung berukuran $19 \mathrm{~cm} \times 16 \mathrm{~cm}$ yang digunakan untuk menyimpan buku Bacusa dan disebelah kanan terdapat kantung yang berukuran $17 \mathrm{~cm} \times 12 \mathrm{~cm}$ yang digunakan untuk menyimpan audio Bacusa. Selanjutnya buku bacusa, buku bacusa ini terdiri atas buku cerita bacusa dan informasi mengenai badak. Ukuran buku ini adalah $15 \mathrm{~cm} \times 21 \mathrm{~cm}$. Buku bacusa terdiri atas 15 halaman dalam 9 lembar. Buku ini didesain dengan menggunakan aplikasi medibang dan corel draw X7. Buku Bacusa menggunakan kertas art carton dengan kualitas ketebalan 190 gram dan menggunakan paperboard untuk bagian sampul yang kemudian dijilid menggunakan ring kawat. Isi audio merupakan dubbing dari cerita yang ada pada buku. Proses dubbing menggunakan handphone lalu diedit menggunakan aplikasi camtasia studio versi 9. (4) validasi/ uji ahli, yang dilakukan pada 3 bidang ahli. Adapun validasi ahli kepada ahli media, ahli bahasa, dan ahli materi.

Tabel 5 Hasil Validasi Tim Ahli Media

\begin{tabular}{|c|c|c|c|c|}
\hline \multirow[t]{2}{*}{ No } & \multirow[t]{2}{*}{ Aspek Penilaian } & \multicolumn{2}{|c|}{ Skor } & \multirow{2}{*}{$\begin{array}{l}\text { NP (\%) } \\
\text { Total }\end{array}$} \\
\hline & & Ahli Media 1 & Ahli Media 2 & \\
\hline 1 & Komunikasi Visual & 97 & 92 & $\frac{189}{210} \times 100 \%=90 \%$ \\
\hline 2 & Rekayasa Media & 14 & 15 & $\frac{29}{30} \times 100 \%=96,67 \%$ \\
\hline 3 & Kelayakan Isi & 25 & 20 & $\frac{45}{50} \times 100 \%=90 \%$ \\
\hline 4 & Mutu Teknis & 28 & 25 & $\frac{53}{60} x 100 \%=88,33 \%$ \\
\hline & Jumlah & 164 & 152 & 316 \\
\hline & NP (\%) & $\frac{164}{175} \times 100 \%=93,71$ & $\frac{152}{175} \times 100 \%=86,85$ & $90.285 \%$ \\
\hline \multicolumn{2}{|c|}{$\sum$ Rata-rata } & \multicolumn{2}{|c|}{$90.285 \%$} & \\
\hline & & Kriteria Kelayakan & & Sangat Layak \\
\hline
\end{tabular}

Berdasarkan tabel 5, hasil validasi media menunjukkan bahwa dari ahli media I diperoleh jumlah 164 dari pernyataan 35 dengan persentase nilai 93,71\%. Adapun dari ahli 
media II diperoleh jumlah 152 dari pernyataan 35 dengan persentase nilai 86,85\%. Berdasarkan hasil validasi media dapat diambil kesimpulan bahwa media pembelajaran puppet book berbasis pembelajaran multiliterasi yang peneliti kembangkan mendapatkan kualitas sangat layak, hal ini dibuktikan dengan nilai rata- rata keseluruhan yakni 90,285\% .

\begin{tabular}{|c|c|c|c|c|}
\hline \multirow[t]{2}{*}{ No } & \multirow{2}{*}{$\begin{array}{c}\text { Aspek } \\
\text { penilaian }\end{array}$} & \multicolumn{2}{|c|}{ Skor } & \multirow{2}{*}{$\begin{array}{l}\text { NP (\%) } \\
\text { Total }\end{array}$} \\
\hline & & Ahli Media 1 & Ahli media 2 & \\
\hline 1 & Kebahasaan & 60 & 59 & $\frac{119}{120} \times 100 \%=99,167 \%$ \\
\hline \multicolumn{2}{|c|}{ Jumlah } & 60 & 59 & 119 \\
\hline \multicolumn{2}{|c|}{ NP (\%) } & $\frac{60}{60} \times 100 \%=100 \%$ & $\frac{59}{60} x 100 \%=98,33 \%$ & \multirow[t]{2}{*}{$99,167 \%$} \\
\hline \multicolumn{2}{|c|}{$\sum$ Rata-rata } & \multicolumn{2}{|c|}{$99,167 \%$} & \\
\hline \multicolumn{4}{|c|}{ Kriteria Kelayakan } & Sangat Layak \\
\hline
\end{tabular}

Berdasarkan tabel 6, mengenai data penilaian validasi bahasa menunjukkan bahwa dari ahli bahasa I diperoleh jumlah 60 dari 12 pernyataan dengan persentase nilai 100\%. Adapun ahli bahasa II diperoleh jumlah 59 dari 12 pernyataan dengan persentase nilai 98,33\%. Berdasarkan hasil validasi bahasa diatas dapat diambil kesimpulan bahwa media pembelajaran puppet book berbasis pembelajaran multiliterasi yang dikembangkan mendapatkan kualitas sangat layak, hal ini dibuktikan dengan nilai rata- rata keseluruhan yaitu $99,167 \%$.

Tabel 7 Hasil Validasi Tim Ahli Materi

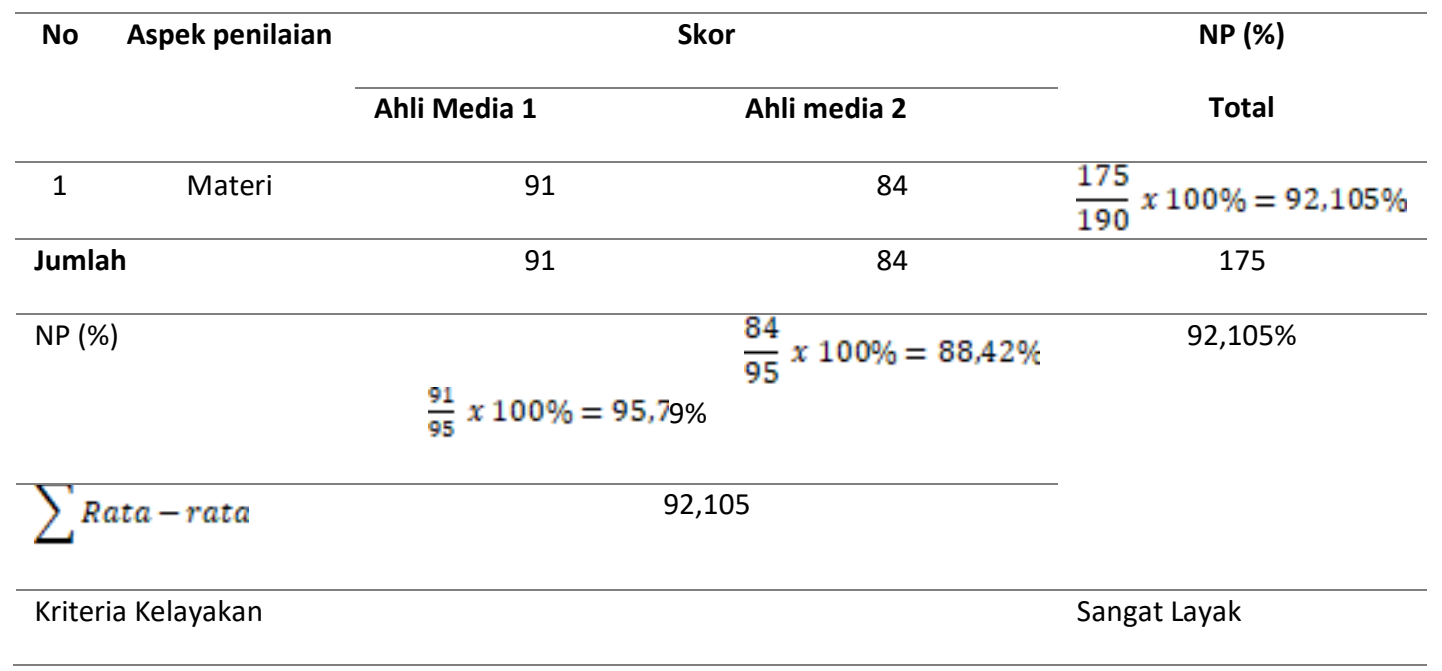

Berdasarkan tabel 7, mengenai data penilaian validasi materi menunjukkan bahwa dari ahli materi I diperoleh jumlah 91 dari 19 pernyataan dengan persentase nilai 95,79\%. Adapun hasil dari ahli materi II diperoleh jumlah 84 dari 19 pernyataan dengan persentase nilai $88,42 \%$. Berdasarkan hasil validasi materi, diambil kesimpulan bahwa media pembelajaran puppet book berbasis pembelajaran multiliterasi yang dikembangkan mendapatkan kualitas sangat layak, hal ini dibuktikan dengan nilai rata- rata keseluruhan yakni $92,105 \%$. 
Tabel 8. Hasil Analisis Data Respon Siswa

\begin{tabular}{|c|c|c|c|c|c|}
\hline \multirow{2}{*}{ Siswa } & \multicolumn{3}{|c|}{ Aspek } & \multirow{2}{*}{ Jumlah skor } & \multirow{2}{*}{ Nilai akhir \% } \\
\hline & Tampilan & Ketertarikan & Kemanfaatan & & \\
\hline Total Skor & 272 & 230 & 77 & 579 & 1930 \\
\hline Nilai Akhir & $97,14 \%$ & $95,83 \%$ & $96,25 \%$ & & $1 \%$ \\
\hline
\end{tabular}

Berdasarkan tabel 8, mengenai hasil respon siswa terhadap media pembelajaran puppet book berbasis pembelajaran multiliterasi diperoleh nilai akhir rata- rata sebesar 96,41\%, hal ini menunjukkan kedalam kriteria "sangat baik". Puppet book berbasis pembelajaran multiliterasi merupakan pengembangan dari media puppet. Jenis puppet yang peneliti kembangkan dalam penelitian ini ialah jenis hand puppet atau dalam bahasa Indonesia disebut boneka tangan. Perbedaan dari pupet book yang dijual dipasaran dengan puppet book yang sedang dikembangkan adalah puppet book ini didesain agar dapat digunakan atau dimainkan secara berkelompok. Pembelajaran secara berkelompok bertujuan agar peserta didik mampu bekerjasama dengan teman- temannya serta mengasah kecerdasan Interpersonal peserta didik. Selaras dengan Alamsyah Said dan Andi Budimanjaya menjelaskan bahwa kecerdasan interpersonal akan menjadikan peserta didik terampil menjalin hubungan dengan orang lain, seperti mudah bergaul, mempunyai kepekaan sosial, negosisasi, bekerjasama dan mempunyai empati yang tinggi (Sukitman, 2013).

Media puppet book didesain dengan beberapa komponen penyerta seperti, puppet badak atau bacusa (badak cula satu) yang merupakan hewan langka dari Banten sebagai asal daerah peneliti, buku yang memuat cerita fiksi dan nonfiiksi, serta audio yang menjadi satu kesatuan media yang menarik untuk mendukung pembelajaran multiliterasi. Selaras dengan ciri dari media dalam pembelajaran multiliterasi antaralain, 1) multibentuk, multikreasi dan multifungsi; 2) bersifat kaya yakni mencerminkan seluruh media literasi otentik yang ada dalam kehidupan sehari- hari; 3) ramah anak, yakni sesuai dengan pengalaman otenstik anak dan sesuai dengan karakteristik anak yang lainnya; 4) elaboratif dan ;5) komprehensif yakni media ini berkenaan dengan berbagai bidang ilmu ataupun konteks budaya (Abidin, 2017).

Media puppet book bersifat multifungsi yang sesuai dengan teori Gardner dan rekanrekannya yang mengatakan setiap anak mempunyai caranya sendiri untuk menjadi cerdas. Lebih lanjut, Gardner menyebutkan delapan kecerdasan yang dimiliki anak dengan porsi yang tidak sama setiap cantik, yaitu : spasial, linguistik, interpersonal, musikal, naturalis, intrapersonal, logis-matematis dan Eksistensial .Sehingga media ini bukan hanya mengaktifkan satu kecerdasan saja tetapi juga beberapa kecerdasan yang diantaranya kecerdasan linguistik, kecerdasan spasial, kecerdasan interpersonal dan intrapersonal (Solikhah et al., 2015).

Puppet book dibuat sebagai media pembangkit dan pembentuk pemahaman, keterampilan, dan peranti untuk menunjukkerjakan pemahaman atau representasi pemahaman dan keterampilan. (Abidin, 2017). Dalam hal ini terlihat dari kemasan buku yakni puppet yang dapat menjadi media pembangkit keantusiasan dan membantu peserta 
didik dalam memahami cerita, serta melatih keterampilan berbicara dengan menggunakan puppet. Desain buku dibuat menarik dan sesuai dengan karakter peserta didik SD, serta audio yang bisa memudahkan peserta didik untuk memahami cerita.

Kemudian buku yang terdapat pada tubuh puppet badak berisikan cerita fiksi, non fiksi. Cerita fiksi dalam buku ini mengangkat tokoh badak cula satu sedangkan nonfiksinya berupa informasi badak cula satu satu sekarang. Tampilan pada setiap lembaran buku, peneliti desain dengan menarik sesuai dengan karakteristik peserta didik. Pemilihan jenis font dan ukuran font untuk tulisan- tulisan pada buku bacusa disesuaikan dengan karakteristik peserta didik dan dibuat menarik agar dapat menarik perhatian peserta didik. Penyusunan kalimat pada buku disusun dengan bahasa yang sederhana dan komunikatif agar peserta didik dapat memahami maksudnya dengan baik. Buku bacusa ini sesuai dengan penjelasan Untari et al dalam Septiani, Dwi dkk (2013) menjelaskan bahwa bahan ajar sebaiknya menggunakan ragam bahasa yang komunikatif agar peserta didik seolah-olah berinteraksi dengan guru melalui tulisan dalam bahan ajar tersebut.

Puppet digunakan peserta didik sebagai media untuk bercerita. Puppet atau boneka merupakan jenis model pembelajaran yang menggunakan media boneka untuk menunjukkan permainan. Penggunaan media boneka dapat menjadi metode bercerita yang efektif dalam pembelajaran, dapat mengembangkan daya imajinasi, pemahaman yang tinggi, mengajarkan siswa untuk bersimpati dan berempati, mengajarkan kebudayaan, dan memlatih peserta didik merespon suatu kejadiaan atau memecahkan masalah berdasarkan apa yang dialaminya, melatih speserta didik untuk dapat mengambil pelajaran dari setiap cerita. Penggunaan media boneka tangan lebih efektif dan bermakna sehingga hasil belajar dapat meningkat (Sudjana, 2019).

Puppet book terdiri atas tiga bagian, yakni puppet badak yang mana puppet digunakan guru dan siswa sebagai media untuk bercerita. Sesuai dengan pendapat Sulianto, et al yang menjelaskan bahwa boneka tangan adalah boneka media dalam pembelajaran, berukuran sebesar tangan pengguna dan dapat dimasukkan ke tangan (Prananta, Yunina Resmi; Setyosari, Punandji; Santoso, 2017). Senada dengan Haula (2016) yang juga mengatakan bahwa media puppet atau sejenisnya memiliki kelebihan dalam meningkatkan keterampilan menyimak, diantaranya mengembangkan imajinasi dan aktivitas siswa dalam suasana gembira, bentuknya yang unik dan menarik dan penggunaannya yang mudah serta mampu mengasah kreativitas guru.

Bentuk puppet dalam media pembelajaran ini memberikan daya tarik untuk peserta didik, sesuai dengan pendapat Gunarti yang menjelaskan bahwa boneka dapat mendorong tumbuhnya fantasi atau imajinasi anak (Prananta, Yunina Resmi; Setyosari, Punandji; Santoso, 2017). Diantara banyaknya boneka yang dapat digunakan dalam media bercerita adalah boneka tangan yang dalam hal ini ialah hand pupet. Boneka termasuk media pembelajaran yang sesuai dengan karakteristik peserta didik SD yang pada usia ini mereka senang bermain. Hal ini selaras dengan pendapat (Chrisyarani, 2018) yang mengatakan bahwa peserta didik SD masih suka bermain, bergerak, dan bekerja dalam kelompok, dan menyukai sesuatu hal secara langsung. Dalam hal ini media Puppet book merupakan media pembelajaran yang sesuai dengan karakteristik peserta didik SD. Hasil penelitian 
pengembangan media puppet book berbasis pembelajaran multiliterasi ini semoga dapat membantu peserta didik dalam menumbuhkan minat bermultiliterasi serta mengembangkan keterampilan berbahasa yang dimiliki peserta didik.

\section{Kesimpulan}

Penelitian yang dilakukan merupakan penelitian pengembangan Research and Development ( $R$ \& D) dengan tahapan pengembangan Borg and Gall yang telah dimodifikasi oleh Sugiyono. Hasil penelitian ini berupa media pembelajaran puppet book berbasis pembelajaran multiliterasi. Hasil penelitian menunjukkan bahwa hasil validasi oleh ahli media termasuk kedalam kriteria sangat layak dengan nilai rata- rata yang diperoleh ialah $90,285 \%$. Hasil validasi bahasa oleh ahli bahasa termasuk kedalam kriteria sangat layak yakni dengan nilai rata- rata yang diperoleh ialah 99,167\%. Hasil validasi materi oleh ahli materi termasuk kedalam kriteria sangat layak yakni dengan nilai rata- rata yang diperoleh ialah 92,105\%. Adapun hasil angket respon siswa pada uji coba lapangan menunjukan 96,41\% dengan kriteria sangat baik. Berdasarkan hasil tersebut, produk akhir yang berupa media pembelajaran puppet book berbasis pembelajaran multiliterasi yang dihasilkan layak digunakan untuk kegiatan belajar peserta didik kelas IV SD. Puppet book yang dikembangkan dapat dijadikan alternatif media pembelajaran. Kepada peneliti selanjutnya diharapkan dapat mengembangkan puppet book dengan menambahkan spesifikasi pendukung materi ajar yang akan diajarkan dan karakteristik peserta didik.

\section{Daftar Rujukan}

Abidin, Y. (2017). Pengembangan Model Pembelajaran Literasi Berbasis Konsep Multiliterasi, Integratif, dan Berdiferensiasi (MID) di Sekolah Dasar. Jurnal Cakrawala Pendidikan. https://doi.org/10.21831/cp.v36i2.13283

Arikunto. (2019). Metodelogi Penelitian, Suatu Pengantar Pendidikan. In Rineka Cipta, Jakarta.

Chrisyarani, D. D. (2018). Pengembangan Media Boneka Tangan dengan Metode Bercerita untuk Siswa Kelas V SDN Sudimoro 2 Kabupaten Malang. Jurnal Bidang Pendidikan Dasar. https://doi.org/10.21067/jbpd.v2i1.2199

Joko Sulianto, Mei Fita Asri Untari, \& Fitri Yulianti. (2014). Media Boneka Tangan Dalam Metode Berceritera Untuk Menanamkan Karakter Positif Kepada Siswa Sekolah Dasar. Jurnal Pendidikan. https://doi.org/10.33830/jp.v15i2.419.2014

Ngalim Purwanto. (2009). Prinsip-prinsip dan Teknik Evaluasi Pengajaran. In PT Remaja Rosdakarya.

Prananta, Yunina Resmi; Setyosari, Punandji; Santoso, A. (2017). Pengembangan Media Boneka Tangan Berbasis Digital Storytelling. Jurnal Pendidikan: Teori, Penelitian, Dan Pengembangan. https://doi.org/10.17977/jptpp.v2i5.10332

Pratiwi, I. (2017). Pengaruh Literasi Ekonomi, Kelompok Teman Sebaya Dan Kontrol Diri Terhadap Perilaku Pembelian Impulsif Untuk Produk Fashion Di Online Shop Pada Mahasiswa Jurusan Pendidikan Ekonomi Undiksha. Jurnal Pendidikan Ekonomi Undiksha. https://doi.org/10.23887/jjpe.v9i1.19994

Ratnawati, L. A. (2018). The Implementation Of School Literacy Program In Bhayangkara Elementary School Yogyakarta. Jurnal Pendidikan Guru Sekolah Dasar. 
Riduwan. (2010). Dasar Dasar Statistika. Pendidikan Dan Perilaku Kesehatan.

Rusman. (2012). Belajar dan Pembelajaran Berbasis Komputer. In Bandung: Alfabeta. https://doi.org/10.14814/phy2.12093

Solikhah, M., Sari, A. K., \& Nurtamam, M. E. (2015). Pengaruh Pembelajaran Berbasis Multiple Intelligences Terhadap Hasil Belajar Matematika Siswa Kelas III SDN Brayublandong Mojokerto. Pedagogia: Jurnal Pendidikan. https://doi.org/10.21070/pedagogia.v4i2.17

Sudjana. (2016). Metoda statistika.Bandung : PT. Tarsito.

Sudjana, N. (2019). Media Pengajaran.

Sugiyono. (2016). Metode Penelitian dan Pengembangan (Research and Development/R\&D). Bandung: Alfabeta. https://doi.org/10.1016/j.drudis.2010.11.005

Sukitman, T. (2013). Konsep Pembelajaran Multiple Intelligence Dalam Pendidikan Ips Di Sekolah Dasar. Jurnal IImiah.

Tim GLN Kemendikbud. (2017). Literasi Digital. In Gerakan Literasi Nasional.

Fakhrudin, Ali, \& Inayati, Arini Uly. (2015). Pengembangan Media Boneka Tangan pada Tema Lingkungan Kelas II SD Negeri 02 Medayu Kabupaten Pemalang. Paper presented at the Seminar Nasional IImu Pendidikan UNS 2015.

Senen, Anwar, Ameliandari, Dea Resti, Pujiastuti, Pratiwi, \& Purwanti, Tusta Rika. (2020). Developing a Hand Puppet Book Media to Improve the Higher Order Thinking Skill and Character of Elementary School Students. Paper presented at the International Conference on Educational Research and Innovation (ICERI 2019). 